\title{
Infestação por Miíase em Prolapso Retal: Relato de Caso e Revisão de Literatura
}

\section{Myiasis Larvae in Rectal Prolapse: Case Report and Review of the Literature}

\author{
PAULO GUSTAVO KOTZE - TSBCP'; JULIANAFERREIRAMARTINS - FSBCP2; \\ JULIANASTRADIOTTO STECKERT²; BRUNOLORENZO SCOLARO ${ }^{3}$; JULIANAGONÇALVES ROCHA-ASBCP'; \\ ERON FÁBIO MIRANDA - ASBCP'; MARIACRISTINASARTOR - TSBCP ${ }^{4}$
}

${ }^{1}$ Chefe do SeCoHUC - Serviço de Coloproctologia do Hospital Universitário Cajuru - PUCPR; ${ }^{2}$ Médicas-residentes do $\mathrm{SeCoHUC} ;{ }^{3}$ Médico-residente de cirurgia geral, estagiário do SeCoHUC; ${ }^{4}$ Médicos do Staff do SeCoHUC.

KOTZE PG; MARTINS JF; STECKERT JS; SCOLARO BL; ROCHA JG; MIRANDA EF; SARTOR MC. Infestação por Miíase em Prolapso Retal: Relato de Caso e Revisão de Literatura. Rev bras Coloproct, 2009;29(3): 382-385.

RESUMO: Introdução: a miíase é uma afecção causada pela presença de larvas de moscas em órgãos ou tecidos do homem e de outros animais. Sua localização preferida em humanos é na pele, com ocorrências descritas nas cavidades naturais. Seu tratamento é baseado na remoção mecânica das larvas e no desbridamento cirúrgico de tecidos desvitalizados. Objetivo: descrição do caso de um paciente com prolapso retal associado à infestação por miíase, discutindo sua incidência, sintomatologia e tratamento. Relato do caso: L.C.S, 36 anos, masculino, com prolapso retal há um ano. Habitante de região rural, com baixo nível sócio-econômico, não possuía banheiros ou qualquer tipo de saneamento básico em sua residência. Ao exame proctológico, evidenciava-se prolapso retal edemaciado, com áreas cavitárias com necrose, secreção purulenta e grande quantidade de larvas de míiase. Realizou-se retirada mecânica das larvas com posterior debridamento cirúrgico. Optou-se pela confecção de uma colostomia em alça do sigmóide, devido à extensa área cruenta com lesão esfincteriana interna. Conclusões: $O$ acometimento da miíase retal em prolapsos é raro, e deve ser prontamente diagnosticado e tratado. Um simples exame proctológico é fundamental para este fim. Salienta-se a necessidade contínua da educação em saúde, bem como se enfatiza a importância dos hábitos de higiene na população.

Descritores: 1. Miíase; 2. Prolapso Retal; 3. Colostomia; 4. Reto; 5. Cirurgia Colorretal.

\section{INTRODUÇÃO}

A miíase é uma afecção causada pela presença de larvas de moscas em órgãos ou tecidos do homem e de outros animais vertebrados. Sua localização preferida em humanos é na pele, com ocorrências descritas nas cavidades naturais, como na boca, no nariz, nos ouvidos, nos olhos, na vagina e no ânus ${ }^{1}$.

Sua apresentação clínica usualmente envolve prurido, associado ou não à dor local. Seu tratamento é baseado na remoção mecânica das larvas com eventual associação de desbridamento cirúrgico de tecidos desvitalizados em consequência da infestação ${ }^{2,3}$.

Os casos de miíase em humanos são mais comuns nos meses de verão e em regiões de clima tropi- cal. Trata-se, portanto, de importante problema de saúde pública face ao forte componente social ligado ao seu aparecimento. Há direta relação com a pobreza, falta de cuidados primários de saúde e de saneamento básico ${ }^{4}$.

O objetivo deste relato é a descrição do caso de um paciente com prolapso retal associado à infestação por miíase, discutindo sua incidência, sintomatologia e tratamento.

\section{RELATO DE CASO}

L.C.S, 36 anos, masculino, solteiro, lavrador, natural e procedente de Colombo (região metropolitana de Curitiba-PR). Encaminhado pela Unidade Bási-

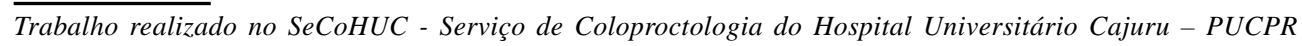
Curitiba - PR. 
ca de Saúde de sua cidade ao Pronto Socorro do Hospital Universitário Cajuru, aos cuidados da equipe da Coloproctologia. O paciente relatava aumento de volume retal às evacuações com redução espontânea há aproximadamente um ano. Há seis meses, referiu piora do quadro, com persistência da protrusão, associada a prurido e dor local. Habitante de região rural, com baixo nível sócio-econômico, não possuía banheiros ou qualquer condição de saneamento básico em sua residência.

$\mathrm{Na}$ chegada ao Hospital, o paciente encontrava-se em bom estado geral, apesar da precária higiene. Ao exame proctológico, evidenciava-se prolapso retal edemaciado, áreas cavitárias com necrose, secreção purulenta e grande quantidade de larvas de miíase (Figuras 1 a 3). Iniciou-se retirada mecânica das larvas de miíase na própria sala de emergência, com posterior desbridamento cirúrgico após avaliar-se

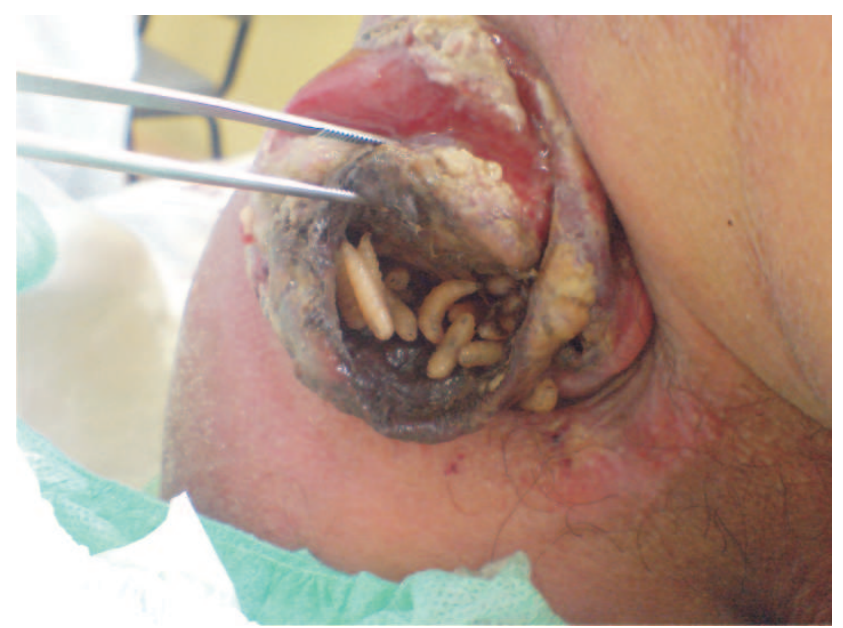

Figura 1 - Prolapso retal com necrose e larvas de miíase.

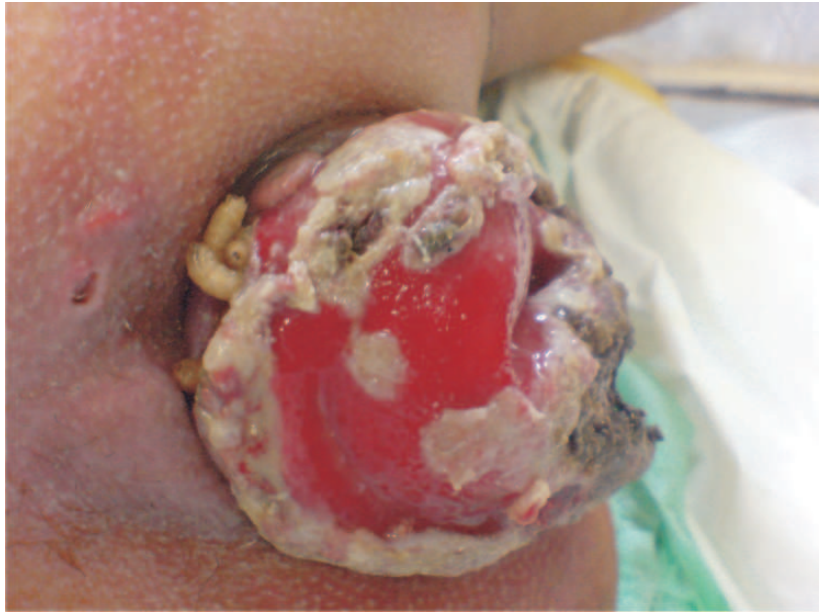

Figura 2 - Edema da mucosa do reto prolapsado com acometimento por larvas de miíase. a extensão da lesão. Durante o procedimento, sob anestesia, foi realizada ressecção extensa dos tecidos retais desvitalizados (mucosa e camadas musculares do reto, assim como parte do músculo esfíncter interno). Optou-se pela confecção de uma colostomia em alça do sigmóide (Figura 4), devido à extensa área cruenta com lesão esfincteriana interna. Associou-se ao tratamento antibioticoterapia sistêmica (ceftriaxona e metronidazol endovenosos) e ivermectina oral na dose de $200 \mu \mathrm{g} / \mathrm{Kg}$. Necessitou de revisão cirúrgica, com extração de mais algumas larvas residuais, no segundo dia de internamento. Observou-se redução do prolapso, com diminuição do edema e bom aspecto das áreas acometidas. O paciente recebeu alta hospitalar no sétimo dia do pós-operatório, com suporte de assistência social, orientações do serviço de estomaterapia e seguimento ambulatorial.

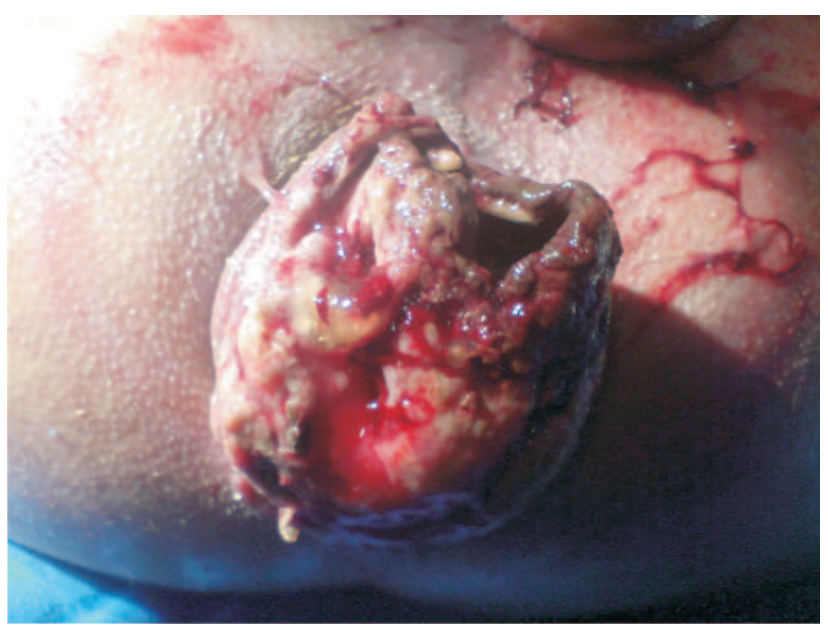

Figura 3 - Extensa área necrótica do reto prolapsado.

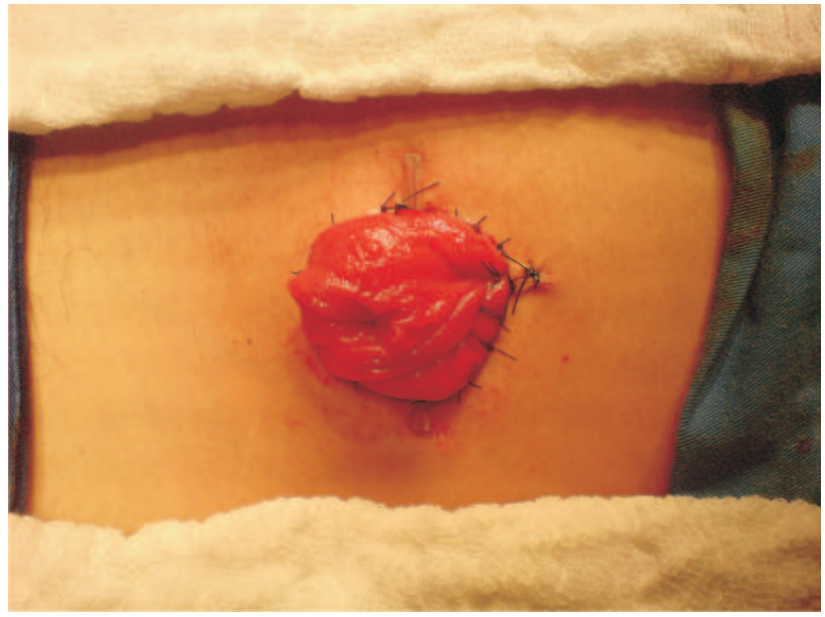

Figura 4 - Colostomia em alça do sigmóide realizada. 


\section{DISCUSSÃO}

A miíase é definida como a infecção ou infestação de humanos e animais vertebrados vivos por larvas de dípteros, que eventualmente alimentam-se de tecido vivo ou morto do hospedeiro 5 . Clinicamente, as miíases são classificadas de acordo com a sua localização anatômica. Podem ser cutâneas, cavitárias e intestinais. Na infecção cutânea, pode ocorrer processo inflamatório semelhante a um abscesso, com invasão da derme ou feridas pré-existentes. Na forma cavitária, desenvolvem-se em orifícios naturais do corpo humano, como boca, nariz, ouvidos, olhos, vagina e ânus. A ingestão acidental de larvas ou ovos pode ocasionar mí́ase intestinal. Várias espécies de moscas são de importância médica por infestarem o homem. No Brasil destacamse a Cochliomyia hominivorax, Cochliomyia macellaria e a Dermatobia hominis 3,4,6,7,8,9. $^{3}$.

A principal forma de apresentação é a infecção cutânea, seguida pelo acometimento cavitário de áreas desnudas, como ouvidos, olhos, boca e nariz. Mais raros são os relatos descritos de lesões no ânus e na vagina, em virtude do uso de vestimentas que dificultam a exposição destas áreas do corpo ${ }^{1,2,4}$.

As miíases humanas são enfermidades frequentes em países tropicais, e ocorrem mais comumente em habitantes da zona rural. Em áreas urbanas, a infestação geralmente ocorre nas áreas expostas do corpo. A maioria dos casos em humanos é descrita em indivíduos com hábitos precários de higiene, baixo nível de instrução, etilistas, diabéticos, imunossuprimidos ou com distúrbios psiquiátricos ${ }^{4}$.

$\mathrm{Na}$ literatura atual não há dados referentes à incidência da infestação por miíase associada ao prolapso retal. Alguns relatos de casos isolados foram eventualmente descritos ${ }^{4}$.

O prolapso retal extenso, em pacientes que evacuam sem saneamento básico, pode colocar o reto em contato com o chão durante a evacuação. Como consequência deste ato, bactérias e larvas podem acometer a mucosa retal, facilitando a infestação por larvas de miíase. Este é o possível mecanismo fisiopatológico do acometimento do prolapso retal no caso estudado.

As manifestações clínicas variam de acordo com o órgão ou tecido infectado. Geralmente apresentam-se com prurido e dor no sítio lesado ${ }^{2,3}$. O simples exame da região acometida e um alto grau de suspeição facilitam o diagnóstico.
O objetivo do tratamento da infestação retal por miíase, assim como nos demais casos secundários, é a retirada completa de todos os organismos invasores. Desta forma, evita-se extensa reação inflamatória, infecção ou granuloma devido a restos teciduais remanescentes ${ }^{2}$.

A remoção das larvas da região anorretal não é um procedimento simples, principalmente pela difícil exposição local. Para o auxílio na identificação e extração das larvas em áreas de difícil acesso, podese utilizar anuscópios e retossigmoidoscópios ${ }^{2,3,5,6}$. Recomenda-se anestesia nas infestações da região anorretal. No caso relatado, devido ao desbridamento ter sido realizado em ambiente cirúrgico, um simples anuscópio teve papel importante na exposição da área desbridada.

A retirada mecânica pode ser realizada simplesmente através de pinças. O desbridamento cirúrgico pode ser necessário nos casos de inviabilidade tecidual. Outra alternativa é a utilização de algumas substâncias para se bloquear a via de respiração da larva, causando a migração desta para a superfície e posterior retirada. Entre elas, destaca-se uma mistura de clorofórmio com turpentina, cloreto de etileno, irrigações com soluções a base de nafta e éter, ivermectina tópica e lidocaína. Hábitos folclóricos citam uso de toucinho, vaselina, cera de abelha, fita adesiva, entre outros $^{1,2,5,6}$. O uso de ivermectina por via oral, em dose única de $150-200 \mu \mathrm{g} / \mathrm{Kg}$, mostra-se eficaz devido à sua rápida absorção, com elevada concentração sanguínea em curto período de tempo ${ }^{2}$. No caso relatado, a retirada das larvas associada ao desbridamento das áreas de necrose do reto e canal anal foi efetiva para o controle da infestação. Utilizou-se a ivermectina por via oral como tratamento sistêmico.

O desvio do trânsito intestinal eventualmente se faz necessário como tratamento associado ao desbridamento. Uma boa opção é a confecção de uma colostomia em alça do sigmoide. Sua indicação ocorre nos casos em que há necrose extensa do reto com amplo desbridamento de musculatura esfincteriana, sinais de infecção local, ou evolução para Síndrome de Fournier. O estoma favorece as condições do local para melhor cicatrização e diminui as chances de infecção por contaminação pelas fezes ${ }^{7,8,9}$.

A infestação de tecidos humanos por miíase é de grande importância para os serviços públicos de saúde. O acometimento da miíase retal em prolapsos é raro, e deve ser prontamente diagnosticado e tratado. 
Rev bras Coloproct Julho/Setembro, 2009
Vol. 29 $\mathbf{N}^{\mathbf{3}} 3$
Um simples exame proctológico é fundamental para este fim. Este relato salienta a necessidade contínua da educação em saúde, bem como enfatiza a importância dos hábitos de higiene na população.

\begin{abstract}
Introduction: myiasis is an infection of human tissues with dipterous fly larvae. It is commonly located in human skin, however, it is described in natural orifices. This condition is treated by mechanical extraction of larvae associated with damaged tissue ressection. Objective: case report of a patient with myiasis infection of rectal prolapse, emphasizing its incidence, symptoms and treatment options. Case report: L.C.S., a 36-year-old male, with rectal prolapse complaints for one year, with bad sanitary conditions. Proctological examination revealed rectal prolapsed with necrosis areas affected by myiasis. Larvae remotion was realized with necrotic tissue resection. A loop-sigmoid colostomy was performed due to extensive perineal wound and internal sphincter damage. Conclusions: rectal prolapse with myiasis infection is rare, and must have prompt diagnosis and treatment. A simple perineal examination is essential. We emphasize continous health education and basic hygiene measures for the population.
\end{abstract}

Key words: 1. Myiasis; 2. Rectal Prolapse; 3. Colostomy; 4. Rectum; 5. Colorectal Surgery.

\section{REFERÊNCIAS}

1. Fares NH, Melo DV, Stucchi N, Carvalhosa AA, Castro PHS, Siqueira CRB. Miíase em Paciente de 10 Anos de Idade: Relato de Caso e Revisão de Literatura. Rev Clin Pesq Odontol. 2005;1(4):49-54.

2. Rodrigues MHL, Aoki L, Nicoletti AGB, Matayoshi S, Fernandes JBV. Ivermectina no Tratamento da Mí́ase Orbitária: Relato de Caso. Arq Bras Oftalmol. 2003;66(4):1921.

3. Hyun DY, Cain MP, Blue-Hnidy DE, Conway JH. Urinary Myiasis associate with Ureteral Stent Placements. Pediatr Infect Dis J. 2004;23(2):179-81

4. Marques AT, Mattos MS, Nascimento SB. Miíase associada com alguns fatores sócio-econômicos em cinco áreas urbanas do Estado do Rio de Janeiro. Rev Soc Bras Med Trop. 2007;40(2):175-80.

5. Manfrim AM, Cury A, Demeneghi P, Jotz G, Roithmann R. Miíase Nasal: Relato de Caso e Revisão de Literatura. Arq Int Otorrinolaringol. 2007;11(1):74-9.
6. Bernhard JD. Bringing on the bacon for myiasis. Lancet. 1993; 342(8884):1377-8.

7. Bhatti HP, Bhasin DK, Sood AK, Nada R, Malla N et al. Intestinal Myiasis Due to Musca domestica: A Report of Two Cases. Jpn J Infect Dis 2002;55(6):191-3.

8. Shivekar S, Senthil K, Srinivasan R, Sureshbabu L, Chand P, Shanmugam $\mathbf{J}$ et al. Intestinal Myiasis caused by Muscina stabulans. Indian J Med Microbiol. 2008;26(1):83-4.

9. Sampson C E, MaGuire J, Eriksson E. Botfly Myiasis: Case Report and Brief Review. Ann Plast Surg. 2001;46(2):150-2.

Endereço para correspondência:

PAULO GUSTAVO KOTZE

Rua Jaime Balão, 975 - ap. 106

Curitiba - PR - CEP 80040-340

Fone/Fax: (41) 3022-5500

E-mail:pgkotze@hotmail.com 